\title{
The transition to general management in South Africa
}

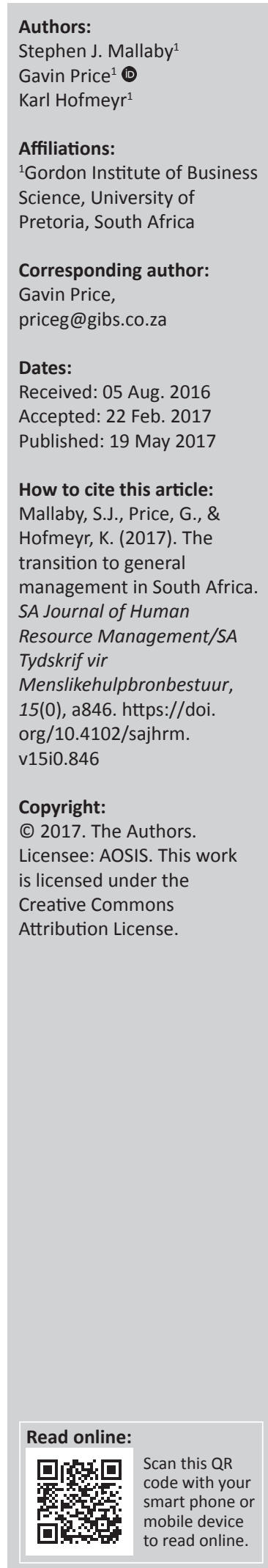

Orientation: Understanding the nature and challenges of making the transition from a functional role to a general management role in South African organisations.

Research purpose: The objective of this study was to gain insight into the obstacles that affect the transition from functional to general management and identify steps that may be taken to overcome these challenges.

Motivation for the study: One of the most difficult crossroads for a manager is making the shift from being a functional specialist to becoming a general manager. New competencies and behaviours are required, as well as a more strategic mind set. If the transition is not made successfully, the manager and the organisation suffer.

Research design, approach and method: A qualitative design was used consisting of in-depth, semi-structured interviews, with 19 senior business leaders who had successfully made the transition. The interviews were used to gather insights into the challenges they faced during their transitions, and how these were overcome.

Main findings: To make the transition successfully, functional managers need to gain relevant experience to prepare them for the broader scope of a general management role. They need to develop appropriate skills, attitudes and personal characteristics. Mentoring is an effective development process. Newly appointed general managers need to learn to let go of control while maintaining ownership, build relationships and strike the right balance between strategic thinking and execution. There are unique aspects of being a general manager in South Africa, such as dealing with Black Economic Empowerment and challenges of race and identity, given the country's history.

Practical and managerial implications: Specific interventions are suggested which are directed at both aspiring general managers and organisations seeking to assist middle managers to make the transition to general managers.

Contribution: This study contributes to knowledge concerning the skills and attributes required by potential general managers, and the practical steps to be taken by South African organisations to facilitate the development of general managers.

\section{Introduction}

Being an effective general manager requires the same things today as it will require tomorrow: the willingness to lead, the openness to learn and an unwavering commitment to creating long-term value. The transition to general management is a change indeed, and it requires serious mental and emotional effort. Frequently, it represents a shift away from everything one has known in the past, and often entails the unlearning of lessons one has spent years trying to make second nature. (Keiser, Pich \& Schecter, 2015, p. 2)

There is a lamentably high degree of failure among general managers, part of which is attributable to leaders failing to transition effectively (Burke, 2006; Sokol, 2017). This may be attributed to the fact that the transition to the general management level requires a profound transformation (Ibarra, Snook \& Ramo, 2008; Sparrow \& Makram, 2015). Given that South African business is in a constant state of flux with issues of political uncertainty, globalisation, emerging economies and competitive pressures, a different style of leadership may be required (Adl, Burnett \& Dapra, 2013; De Vries, Sexton \& Ellen, 2016; Hall \& Rowland, 2016). This may affect the ability of a leader to transition because he or she has to deal with the new role in a rapidly changing business environment. The objective of this study was to gain a better understanding of the transition that managers must make to general management in the South African context. How do managers make the transition and how do they overcome the associated challenges? The study explored the 
challenges faced by managers making the transition, so that recommendations for the development of general managers in South Africa could be made.

Drotter and Charan (2001) proposed that the change from a functional role to general management role results in increased pressure to move away from individual tasks and activities to those more aligned with the needs of the business, thus veering the leader into unfamiliar territory. The transition is considered to be one of the most challenging experiences for leaders, with a high potential for failure (Ibarra et al., 2008; Watkins, 2012). Some managers, when faced with the challenge of being in unchartered territory and dealing with unfamiliar scenarios, tend to fall back on what they know best and rely on past behaviours. Despite the common conception that 'what got you here won't get you there', many managers fail to adopt this principle (Goldsmith \& Reiter, 2007; Reimer \& Meighan, 2017).

This study was prompted by the observation that many organisations in South Africa have struggled to perform as a direct result of poor leadership. Managers are often functionally competent, but this does not mean that they will become good leaders. To some extent, this relates to the 'Peter Principle', which suggests that people are promoted to their level of incompetence (Lazear, 2004; Maroun, 2014; Tan, 2014). In addition to highlighting the typical challenges associated with the transition into general management, the study also aimed at understanding those challenges that are specific to South Africa.

Referring to leadership in Africa, De Vries et al. (2016) observed that the continent presents a unique context of study for leadership scholars because of its diversity of ethnicities, cultures and languages. South Africa, given its diversity and the transformation it has experienced since the advent of democracy, should be a rich source of insights for a study dealing with leadership and general management. South Africa is also a microcosm of the volatile, uncertain, complex and ambiguous world in which organisations need to survive and thrive (Bawany, 2016).

\section{Literature review}

\section{General management}

Warner and Witzel (1997) defined general managers as executives who are capable of managing the entire company. They need to not only understand business disciplines such as finance, operations, marketing and human resource management but also have the ability to develop a vision and motivate people to achieve the organisation's goals. Kaplan and Kaiser (2003) noted that the general manager needs to adopt a strategic leadership approach, which requires a different level of thinking and encompasses how broadly a leader thinks about the company, aligning the vision and strategy, growing the business and setting long-terms goals. Kates and Downey (2005) suggested that one of the most important talent management efforts of a business is to develop a strong pipeline of general managers.
Much has been written about the difference between management and leadership, and although it is not a new concept, it remains relevant. While not all leaders are managers, and not all managers are leaders, the general manager has to develop strong leadership competencies (Chiu, Balkunid \& Weinberg, 2016; Gosling \& Mintzberg, 2003; Hill, 2003; Lord \& Hall, 2005; Mintzberg, 1973). This is a theme throughout the study. The need for the manager to develop as a leader requires the manager to shift away from the 'doing' aspect to that of 'being', and in the process empowering others to focus on execution. Watkins (2012) suggested that the challenge is over-managing the old familiar functions and under-managing the new ones. He described this as moving from a support cast member to the leading role, and providing both guidance and direction.

\section{Organisational hierarchical levels}

Drotter and Charan (2001) developed a six-passage model to illustrate the various levels of leadership within an organisation and the requirements of the leaders at each level of a 'pipeline'. Each of the turns in the pipeline is considered to be a significant event. The concept of multiple levels of leadership has been described as a journey that a leader has to traverse with six pathways and five crossroads (Freedman, 1998), as reflected in Figure 1. This aligns with the principles of Drotter and Charan's (2001) pipeline of changing responsibilities and accountabilities across the various levels.

Drotter and Charan's (2001) and Freedman's (1998) frameworks are further supported by Watkins (2012), who described the transition between the various levels, particularly from specialist to generalist, as particularly difficult. This study focuses on the transition from functional to general management (Crossroad 3). It is at this juncture that there is the highest risk of failure (Bawany, 2016; Freedman, 2011).

\section{Facilitators and inhibitors of transition}

There are numerous factors that contribute to a successful transition between the various organisational levels, in particular from functional to general management. For example, leadership development and learning processes are considered to be major factors impacting an effective transition (Drotter, 2010; Hall \& Rowland, 2016; Khoreva \& Vaiman, 2015). Although there is agreement about the need for development, Hackman and Wageman (2007) contended that it is not so much about what leaders are taught, but rather how leaders should be helped to learn. McCall (2004) argued that experience plays the most important role in leadership development, and any development should be focused on assignments that will help leaders gain experience and build their knowledge. Similarly, Thomas (2008) emphasised the value that can be gained from on-the-job and off-the-job experiences. Freedman (2005) argued that experience gained through traversing the career crossroads is essential, and skipping any of the crossroad levels will have a negative impact. 


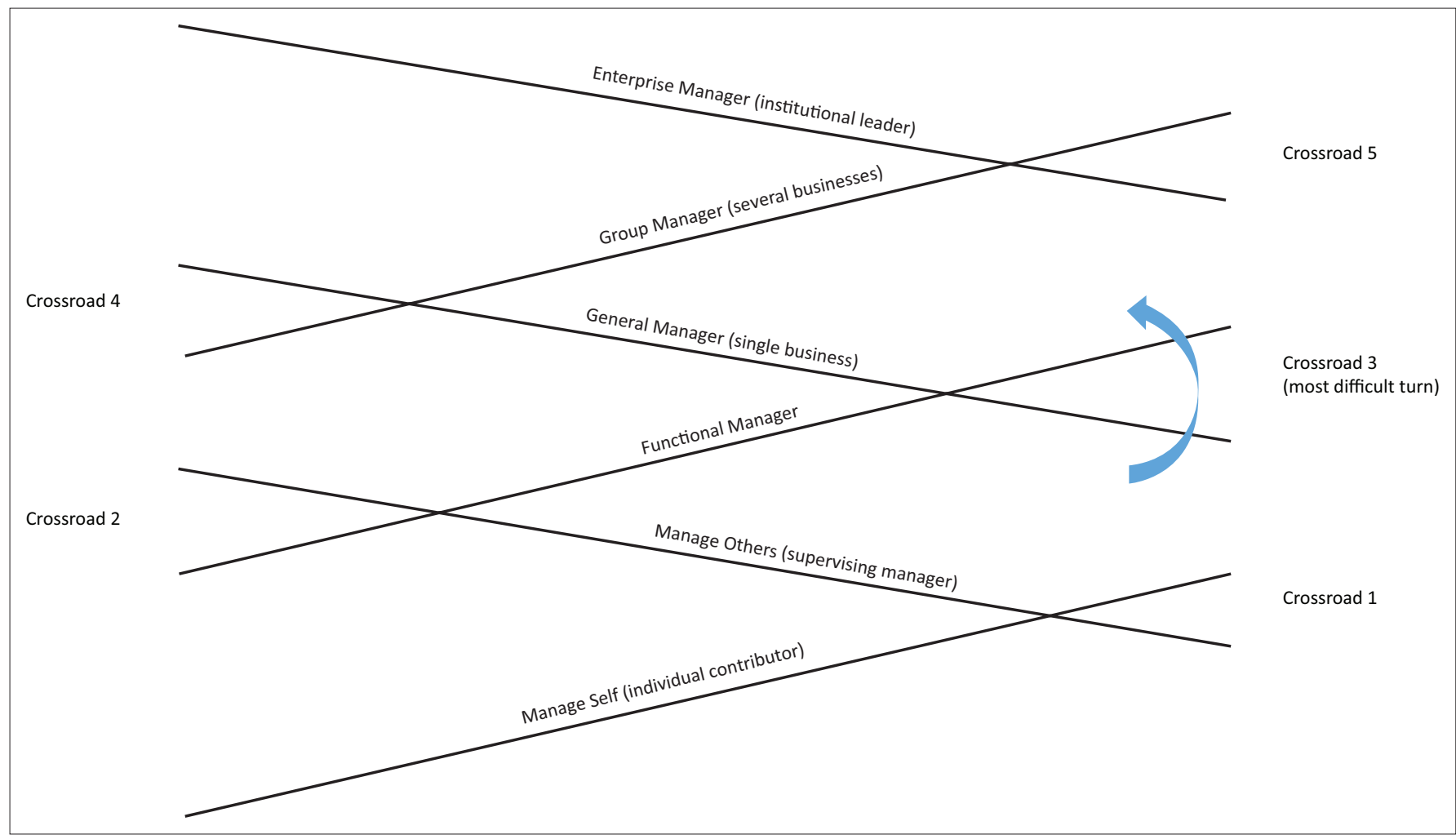

Source: Adapted from Freedman, A.M. (2005). Swimming upstream: The challenge of managerial promotions. In R.B. Kaiser (Ed.), Filling the leadership pipeline (p. 27). Greensboro, NC: Centre for Creative Leadership

FIGURE 1: The six primary pathways and five basic career crossroads.

Current research suggests that the effective transition to general management is impacted by many elements such as improving skills and competencies (De Meuse, Dai \& Wu, 2011; Lord \& Hall, 2005; Mumford, Campion \& Morgeson, 2007), and gaining experience and knowledge (Hackman \& Wageman, 2007; McCall, 2004). Boal (2000) and Goldman, Cahill and Filho (2009) added the elements of developing strategic thinking, building a vision and motivating others, and receiving coaching and mentoring (Berg \& Karlsen, 2016; Goldman, Wesner \& Karnchanomai, 2013). This study draws on these propositions as a frame for the research. Deep personal aspects also impact the ability to transition, including going through transformations (Day \& Harrison, 2007; Ibarra et al., 2008) and changing behaviours and attitudes (Boal, 2000; Burke, 2006; Kaiser, 2011). In addition, personal traits such as character, personality, competence, confidence, self-awareness and the change in activities and tasks play an important role (Bonoma \& Lawler, 1989; De Meuse et al., 2011; Freedman, 2005, 2011; Pietersen, 2015).

To illustrate the number and complexity of factors impacting successful transitions, De Meuse et al. (2011) identified 67 competencies that had to be developed to different degrees across organisational levels. The significance of competencies receives further support from other researchers, and a framework depicting six key managerial competencies is presented in Figure 2 (Hellriegel, Jackson \& Slocum, 2005). Three of the competencies (communication, teamwork and self-management) fall into the category of 'emotional intelligence' as defined by Goleman, Boyatzis and McKee
(2013). They refer to the need for leaders to be intelligent about emotions and the fact that a leader's moods and actions directly impact those they lead. Emotionally intelligent leaders inspire loyalty, encourage innovative solutions and build strong teams and lasting relationships. Goleman (1998) defined that emotional intelligence consists of self-awareness, self-regulation, motivation, empathy and social skill.

While there is extensive literature on generic factors universally, which may inhibit or facilitate the transition, there is very little literature covering aspects that are specific to South Africa.

\section{The nature of the transition}

Kaiser (2011) suggested that managers face different challenges as they transition to higher job levels, and despite extensive research on theories relating to leadership, the literature focuses more on the organisations' process of transition and transformation and less on the leaders' journey (Hiller, DeChurch, Murase \& Doty, 2011). The transition to general management requires that the leader goes through a unique transformation, which requires him or her to do things very differently from the way they have been done in the past (Burke, 2006; Goldsmith \& Reiter, 2007; Kilner, 2015; Watkins, 2012). Novice leaders may well gain the basics of management, but this does not guarantee being able to understand complex organisational and strategic factors (Ibarra et al., 2008). Freedman (2011) made reference to the 'distressed manager in transition' who may fall back on previous ways of solving problems, whereas the new 


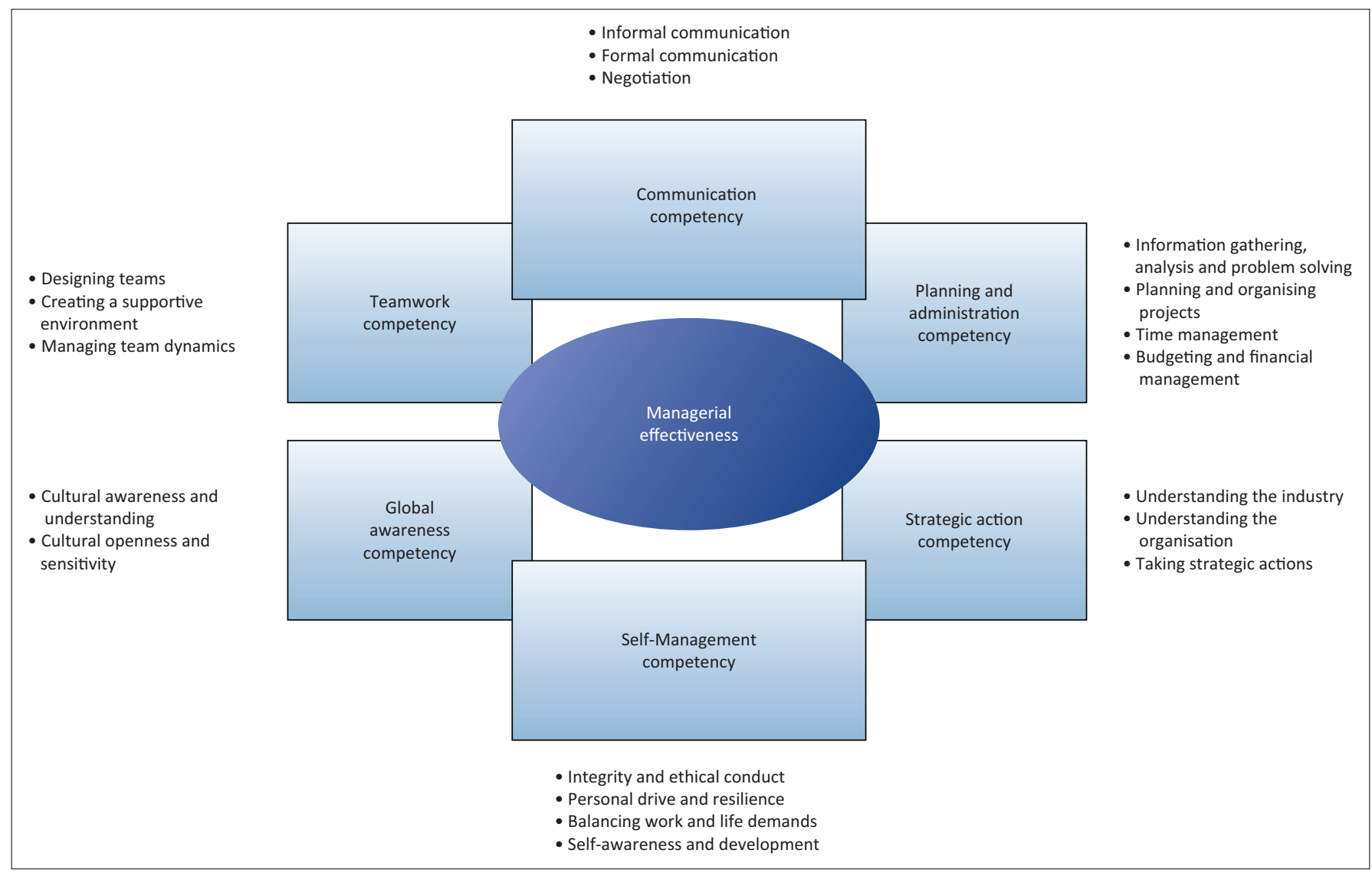

Source: Adapted from Hellriegel, D., Jackson, S., \& Slocum, J. (2005). Management: A competency-based approach. (9th edn.). Mason, IA: South-Western FIGURE 2: Six key managerial competencies.

problems are of a different nature and therefore the old solutions are no longer effective. While the term 'hierarchy' implies an upward structure, newly promoted leaders must not take the perspective of sitting on top but should rather consider themselves to be part of the organisation and integrating themselves within it by collaborating and building trust through relationships (Watkins, 2012).

The challenge for the new general manager is to determine what to continue and what to discontinue. The leader may get trapped in the dynamics of 'betwixt and between', where they feel stuck between the identity of who they were in their previous role and who they need to be in their new role (Bandow \& Self, 2016; Freedman, 2011; Nicholson \& Carroll, 2013). Similarly, Boal (2000) argued that a leader will transition through six phases, which include the honeymoon, learning curve, constant, random, null and lastly rigor mortis. If leaders remain stuck in previous behaviours, they will become a liability to the business. In addition to this shift in identity, Day and Harrison (2007) suggested that there is a shift away from 'who I am' as an individual to 'who we are' as a collective. The general manager must shift away from the functional and operational leadership perspectives as these entail getting involved in the details of the business and focusing on short-term thinking and activities. Too much emphasis on operational details can be a hindrance, specifically when taking on more senior roles (Ibarra et al., 2008; Kaplan \& Kaiser, 2003).
From the review of the literature, it appears that there is still a need for further research to gain an understanding of the general management transition process in a South African context and, to this extent, four research questions were formulated:

- Research question 1: What are the factors that facilitate or inhibit the transition to a general management role?

- Research question 2: Are general managers aware of what they must 'let go of' and the identity transformation they will go through?

- Research question 3: What are the challenges of shifting from functional and operational activities to strategic perspectives?

- Research question 4: What, if any, are the unique challenges of general manager transitions for general managers in South Africa?

\section{Method}

The topic of leadership transition involves a high degree of social involvement and interaction with the environment and within the organisation. According to Saunders and Lewis (2012), business situations are unique and complex and involve a particular set of circumstances and individuals, and for this reason, an interpretive and qualitative approach was used.

The study's focus was on senior business leaders in South Africa who had successfully transitioned to the 
level of general manager or beyond. Purposive sampling was used to identify the individuals to be interviewed. In addition, the sampling process also involved limited snowball sampling as certain interviewees were requested to provide referrals to other C-level individuals. The aim was to select a heterogeneous sample and respondents were selected from a diverse set of business types and industries. To ensure sample diversity, an attempt was made to avoid selecting more than one sample member from the same company, and this was only done in one case where three participants were from the same listed company. By selecting a heterogeneous sample, it was possible to identify trends and patterns that emerged.

Pilot testing was undertaken with three participants who met the criteria of the study to ensure the validity of the questions created to answer the main objective of the study. The feedback from the pilot testing was positive and helped to refine the introduction to the interview as well as make slight amendments to some of the questions. Face-to-face interviews were conducted with 16 experienced C-level executives who had successfully navigated the transition to general management. The aim was to achieve a saturation point where no new relevant information was being provided. Ten of the interviewees were Chief Executive Officers of major companies, and two were Chief Operations Officers. The remaining seven were in senior general management positions.

The interview questionnaire consisted of 20 open-ended questions that covered the relevant themes and types of questions. It was found that all of the interviewees were very open to being approached and spoke freely. The interviews were conducted during business hours and each took approximately $1 \mathrm{~h}$. The interviews were recorded and transcribed, and two separate content analyses were undertaken by the authors to interpret the responses.

\section{Findings}

\section{Research question 1: What are the factors that facilitate or inhibit the transition to a general management role?}

The first question probed the respondents' personal career journeys to establish what may have facilitated or hindered their growth into a general management role. Three broad themes emerged.

\section{Education and mentoring}

The strong theme to emerge was the perceived need to have a solid knowledge-based foundation and that a high quality education, both secondary and tertiary, was a powerful enabler. Its importance was articulated through statements such as: '... the key thing is to get an education. It is very important I think. It gives you a good basis of knowledge'. Another participant proclaimed:

I was fortunate enough to get a good education and like I say, my dad worked day and night to put us through school. So he sent me to a Private School. South Africa didn't have the opportunities for me in those days so I went to Swaziland.
This demonstrated the value of a high quality education for South African business leaders is. Eight of the 19 participants indicated that they had achieved some form of higher academic qualification, whereas two participants indicated that they moved up the corporate ladder despite only holding a high school qualification. In most instances, a mentor or support structure was identified as being beneficial: 'Key factors for me were having mentors and having support structures in place'. The other participants made no mention of their academic qualifications.

\section{Work experience}

Interviewees provided a brief history of the experience they had gained over the years working in various functional and technical fields. During their careers, each participant had been exposed to an average of four different areas of the business. Management, finance and executive positions were the fields where they had gained most of their experience. Working across a range of areas seemed to be a key factor in the preparation for a general management role. One of the interviewees commented as follows:

I was ten times more skilled than anyone else at that stage. Everyone else had got there by being a merchant or an HR person, but no-one had the breadth of skills that I had.

\section{Skills, attitude and personal characteristics}

Other elements that facilitate the transition were reflected in the participants' skills, attitude and personal characteristics. Respondents appeared to be very goal-driven and had a high propensity to actively seek out learning experiences, often combined with an entrepreneurial spirit. Reading, observing and questioning the status quo is reflected in one of the comments as a means of gaining knowledge to further their career advancement:

I read enormously around business, and I always have, so I do. I read business books - so that's part of it. And I will then roll out the concept, I have done that over the years ... I mean for me this business I think about probably ... 24 hours a day. It's a project. For me business is like playing a game, its Monopoly, you've got to keep trying to win.

\section{Research Question 2: Are general managers aware of what they must 'let go of' and the identity transformation process they will go through?}

Interviewees were aware that a fundamental change takes place with the transition to the new role. In response to research question 2 , four key themes were identified.

\section{Letting go of control while maintaining ownership}

Respondents noted that successful leaders adapt their behaviour, often by letting go of certain skills and adopting new ones. Those who are not effective revert back to their comfort zone and try to lead from a functional as opposed to a strategic perspective. Although there was a realisation that general managers need to adopt a more strategic role, they still find this a difficult part of their transition. They feel that they could be losing control of their power base: 
In a functional role environment, your power base tends to be knowledge and skills, and you tend to be authoritarian ... whereas true general management leadership is all by influence ... and so that transition, never mind your skill base, is how to get someone to go from power-based leadership to influencebased leadership is very tricky. And that is probably the harder one, probably harder than unlearning all the things that you learnt as a financial guy.

The temptation to fall back onto one's historic strengths is very powerful, particularly when problems arise, but interviewees noted a definite need to transition from a power base role to a leadership role by letting go of power and managing by influence instead. One of the CEOs illustrated this internal conflict by stating that:

\footnotetext{
... the temptation is very strong to fall back on your ... comfort zone, the experience that you had. So I had to broaden my perspective. I had to deepen my insight into different things; I had to become a lifelong student in the art and science of leadership.
}

Finding ways to ensure that they do not revert to managing according to their functional area of expertise, respondents expressed the need to learn to trust others and draw on other people's strengths to support them as leaders. Combined with this was the realisation that they could not do everything themselves. They were aware of the need to delegate responsibility:

... you see a lot of guys move from a supervisory role into a general management role, and you probably can see them around you: the guys who try and hold on to everything and don't tell anybody anything and don't trust anybody. You can't do it all, you have to trust people.

Respondents all acknowledged the need to let go. Through making a conscious decision to empower their subordinates and learning to step back and wait patiently for the subordinate to perform the function, it frees up their time to concentrate more on strategic issues. However, they also acknowledged that their responsibility includes reflecting on what value they can add by performing the function themselves, compared with the implications of delegating the task to a subordinate who does not perform adequately. Ultimately, they take total ownership of any outcomes:

You actually have to teach somebody how to put the intervention in place. You have got to physically ask yourself the question, 'Should I be doing this?' No. What is the worst thing that can go wrong if I don't do it? The report can be wrong. They can re-do it.

\section{Personal characteristics and relationships}

Some of the interviewees reflected that when they were promoted, they tended to become distant as they felt that they should communicate and operate at a different level from their peers. Some put this down to the possible arrogance of the leader and others explained it as being a consequence of the leader realising the added responsibility of the new role: 'Well you know what? I think that when you have to assume responsibility literally for everything, I think it changes you'. Being promoted to the role of general manager initially instils a sense of pride in the individual and there is a danger that this could lead to arrogance. It has been a journey of hard work and dedication to reach this level of management. Some of the interviewees said that they experienced a sense of entitlement to be in the new role but quickly realised that their behaviours and attitudes needed to be adjusted. It was noted that newly promoted general managers tended to 'underestimate the power of quality relationships' since 'the more senior you become, the more critical the relationships are'.

Interviewees emphasised the importance of building good teams. This begins with developing good relationships and involves some adaptation of personal characteristics, such as reduced arrogance:

Some characteristics have to change ... You can't be the arrogant, obnoxious individual because that is just you - when you have teams around you and different people and different characters, then you have to adapt accordingly.

One participant had a different opinion however, stating that older general managers may not be able to adjust their relationship building behaviour, as they have become too set in their ways. Managers with strong characters find it particularly difficult to adjust their behaviours when they are more established and entrenched in their ways.

Some of the general managers admitted to becoming less tolerant of poor performance. They become aware of their responsibility towards the success of the whole organisation:

I think it is not just that you change but I think that people change in their behaviour towards you as well; because I think you become less tolerant of people either withholding information or giving you wrong information, and I think that when you are managing a team of people, whether it is like 5 or 15 people as a general manager, your ability to deliver on your objectives is actually $100 \%$ reliant on the people that are working with you, and when you hold the ultimate responsibility I think it literally changes your attitude towards non-performers.

\section{Insecurities}

The transition to general management can also lead to insecurities. When promoted to the general management level, executives can feel overwhelmed and unsure of themselves:

I think $99 \%$ of the time the guys that move into general management for the first time are completely overwhelmed and you're thinking and you are treading water just faster and faster.

Realising the extent of responsibility involved, coupled with the exposure to new and unfamiliar areas of responsibility, is likely to be challenging. General managers respond to their insecurities in various ways:

... trying to get to grips with things that I wasn't trained in, you know. So I was suddenly just feeling uncomfortable in my ability because I didn't know exactly what the financial story was. 
The new general manager would like to feel in control of everything but experiencing feelings of insecurity sometimes results in a withdrawal to previous comfort zones. Particularly when problems arise, they might react by re-taking control of the operational activities where they previously excelled.

On the contrary, successful general managers find ways to deal with their insecurities and grow their characters and adapt behaviours to do so. By addressing their insecurities through reflection and support, they are able to identify what changes they need to make to manage effectively and succeed. This requires a level of self-awareness. They commit to growing their knowledge and skills at a higher level to gain a better understanding and reduce their insecurities:

... you need to be able to hold that mirror up to yourself and actually not have an idea of who you are or what people think you are, but somehow get in touch with reality. So that is about people close to you, HR, colleagues, actually saying 'well you know what, this is what people are saying and this is what people think' - those are the things which ultimately determine whether or not you are going to succeed I think.

\section{Courage in the face of loneliness}

The final theme was the need to have courage in the face of loneliness. Much of the transition to general management appears to involve changes in self-perception or identity and this can be a lonely journey. They find themselves in a position where they have become solely responsible for the whole and are no longer just part of a team. The responsibility that the general manager now holds places a burden on their shoulders and they feel they need to 'grow up' as was stated by one respondent: '... planning horizon changes, [and their] sense of impactfulness changes'. Similarly: '... it becomes lonely in the sense that it is you and your staff, as opposed to you working in a team with your peers'. One of the coping mechanisms reported was that general managers develop their intuitive, gut instinct that they learn to trust. After being in the business for some time and having developed a general understanding of the mechanics of the organisation, they have usually developed an intuition for the daily happenings in the business and can quickly identify any potential problems:

Somebody asked me the other day if I knew how many contracts we had and I said 'I think 60 ' and the answer was 59 .... Now that is an intuitive feel that you develop after connecting things ... because it's the gut feel you require.

In addition to using their intuition, having good relationships with peers and colleagues is a safety net and support system for the general manager. While the general managers acknowledge their lonely role, they also realise the importance of engaging with others and building relationships of trust and respect.

\section{Research Question 3: What are the challenges of shifting from functional and operational activities to strategic perspectives?}

General managers were aware of the need to shift their management focus when taking on the new role. The participants were vocal about the shift in focus that was required and the challenges that arose as a result. The challenges experienced by general managers were grouped under five main themes.

\section{A shift of focus and the definition of strategy}

The majority of the participants acknowledged that there was a need to shift their focus to be more strategic when taking on the general manager position. However, the participants indicated that people moving to the new role had differing understandings of what strategy and leadership entailed:

Many of them, or the majority perhaps ... remain super-duper general managers, relatively few embrace the strategic tasks of leadership ... So the common problem is that they get stuck in the management rut. So they still put all, or the bulk of, the emphasis on the functions of management, to plan and to organize and to control and they fall back on their sort of strong points and their knowledge, their insight, their functional competence ... but they fail in some instances to come up with the strategy that will create a better tomorrow.

The view was expressed, however, that the emphasis placed on strategic as opposed to operational elements does depend on the situation.

If you are in the fortunate position of becoming general manager of a company that is growing rapidly and is running slickly you can afford to be more forward looking. So I think at a principle level, yes, but it does rather depend on the specific situation and sector .... So if you become GM of a company that is sinking like a stone, I think you're tactical ...

From the interviews, the consensus was that taking on the role of general manager required a change in focus, but this shift was not necessarily a clear cut shift to a strategic focus. Strategy execution is vital, but general managers are often only drivers of the strategy, which is determined at a higher level. The view was expressed that the general manager cannot avoid having a tactical focus at times to develop, inspire and motivate employees, with the ultimate goal of achieving the organisation's strategic objectives:

I think that as I have gone through in life, what is strategic is very broad decisions. Most of what we operate with at general manager level is tactical, although we might perceive it to be strategic. So I think what we have got to understand is how we take the people in management of the business and expose them to strategy, because if they understand in their heart the logic behind a strategic decision the rest of the decisions on the tree just become easy.

General managers need to learn the complexities of the business and understand how to change their behaviour to align with more strategic thinking. They need to become involved in all aspects of operations and develop relationships with stakeholders so that they are able to establish the success factors and potential pitfalls of the business. They also need to establish boundaries and communicate what they expect of others: 
... for six months you are going to run your ops ragged, you are going to be working 12 to 16 hours a day, I understand all of that, you have to learn about the people, develop the relationships. You have got to learn who the suppliers are, you have to ... visit all the customers, figure out what the success factors are for this particular business, and that is going to take you a long time to do.

Another interviewee expressed the view that:

A lot of people don't communicate boundaries, so you wind up in a leadership or management position and you don't set the boundaries for six months! People are pushing to see where the boundaries are. No-one taught me that, I observed that from someone else, years ago.

Experienced general managers seem to be aware that they cannot do everything themselves, and a vital success factor for them is to build a strong team of people who have the necessary skills and who they can trust. They often find it challenging to let go and trust that the work can be done by someone else as effectively as, or even better, than they can. However, successful general managers learn to delegate and allow their subordinates to develop. In this way, the team as a whole is strengthened and the individuals within the team experience a sense of empowerment and trust:

I know some people are really good at it and other people surround themselves with people that are really good at it, and I think it is a question of realising in which arenas you should play and it is actually very important that the people that are closest to you and are your direct reports, can feel secure enough to give you honest feedback.

\section{Relationship building}

Relationship building was another key element identified by respondents. The ability to build and maintain strategic relationships came as a challenge for many general managers. Some came from a background where they did not need to engage and invest heavily in relationships, but moving into the role of general manager forced them to develop their emotional intelligence. They have to be able to build relationships and manage both upwards and downwards within the organisation as well as laterally and outside the organisation. Formal relationships exist naturally within the work environment but in order to be truly effective, the general manager needs to ensure that a good level of informal contact occurs: '.. the majority of my conversations I have are informal. You can be more honest informally, there are no people watching'. A similar observation was: 'I have to get through to the individuals. And that is a time-intensive activity, you have to walk, get around, talk, understand, and listen with empathy'.

\section{Realisation that a broadening of skill sets was required}

A further theme was a realisation that a broadening of skill sets is required. The participants indicated that there can be a gap that exists for people transitioning to the role of general manager. These managers might know the theory of business, but a theoretical understanding of business is not enough as argued by one interviewee:
I think also there is a belief, you know people say if you do an MBA you can do any business, but I don't believe that. They say we can come here, we are teaching you every aspect of business management. So in theory I should be able to go and run a bank or you should be able to go and run a radio station - but I don't believe that.

The participants outlined some of the competencies and qualities they had to learn when they transitioned to the leadership role. These are depicted in Figure 3.

Human capital management and financial management were two other topics that were mentioned a number of times as challenges for the general manager. Relationship building and performance management were seen as central to the general manager's skill set:

... the people challenge. I think that is one where I think sometimes that has been more of a challenge, to find that. Where if I look at some of my business mentors they fired people a lot more lightly than I have been able to. So that for me has been the biggest challenge because I struggle with that. For me, I think it is a failure if I have to fire somebody, because it means I haven't worked hard enough to make them productive.

With the responsibility for financial management being placed on the general manager's shoulders, they tend to feel ill equipped to take on the burden of the financial well-being of the organisation. This is despite the fact that they often have the theoretical background necessary but lack practical experience in financial management. One of the interviewees illustrated his reactions as follows:

And then when I was appointed as the CEO of the organisation, well the first challenge I had was, I had to accept ... responsibility for the bottom line performance, sustained profit growth, quality earnings. So that was the immediate challenge. So previously I could talk rather easily about return on market and investment, but when I was given the overall task or responsibility for the financial health of the company it was a different ball game.

\section{The need to gather information}

When transitioning into the role of general manager, the participants indicated that they experienced challenges around the lack of information available to them. They had exited roles where they had complete functional control, and in their new positions, they experienced an information gap. One participant suggested that the lack of information was as a result of management higher up the corporate hierarchy, not filtering information down. Another participant explained that the lack of information was a result of taking on additional responsibility and having less time available to digest the information:

Learning to deal with incomplete information and that is something I deal with now, every single day. The more you are in control of your environment the more information you have; the more you move up the less information you have and the less time you have to digest it. One of the big transitions you have to make is learning to manage with incomplete information.

To combat this challenge, the general managers would generally find ways of gathering relevant information for 


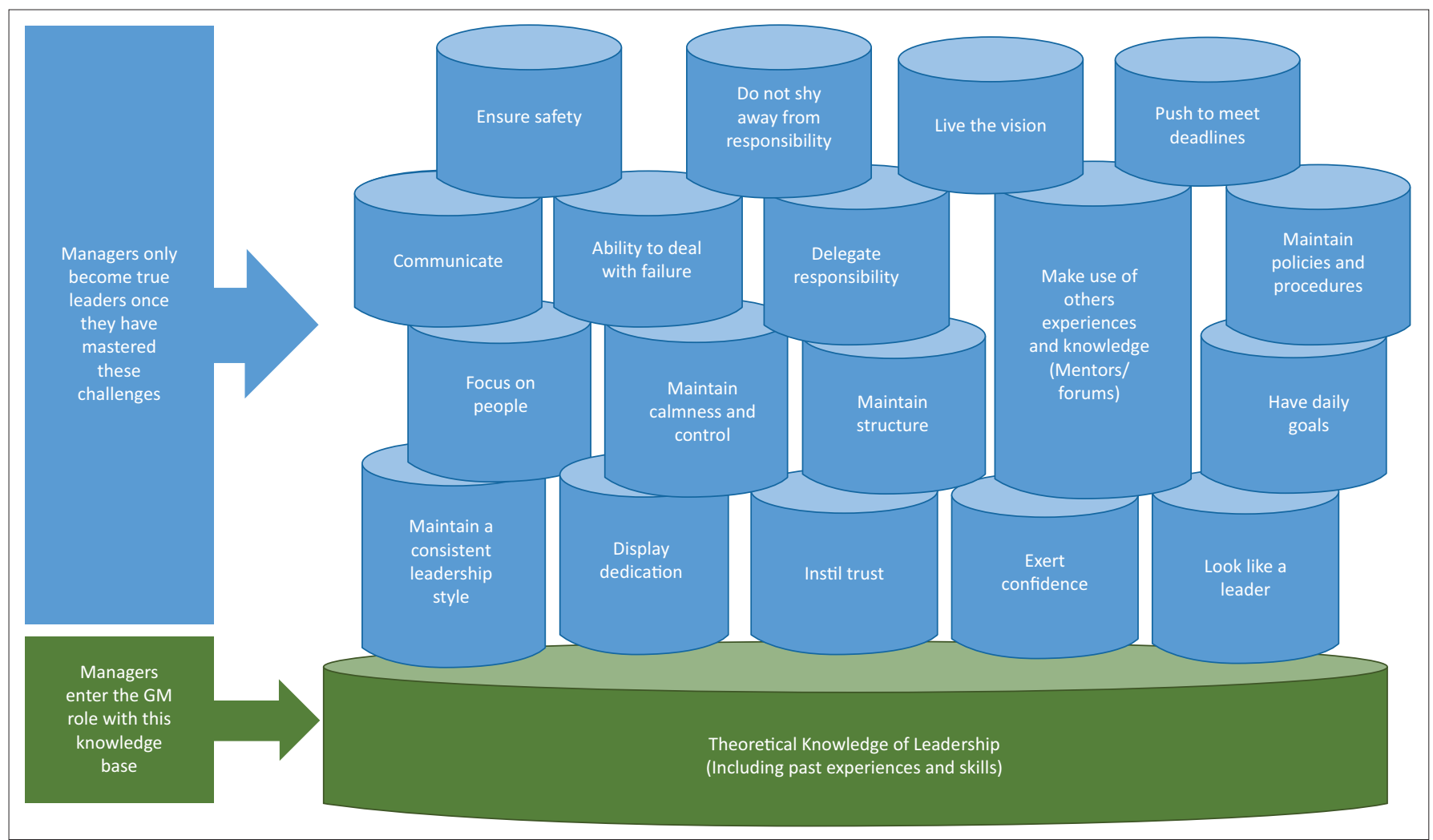

FIGURE 3: Mastering the leadership role (coded from verbatim comments).

themselves. Some choose to further their academic qualifications, some choose to keep abreast of things through reading as much as possible and some spend time researching and reflecting. The most utilised method of gathering information, however, was to engage, watch and learn on the job. '... so I was going out and selling with the sales people, I was servicing, I was learning the business, I was learning'.

\section{The need to set boundaries}

A concluding theme that built on the aforementioned themes under this research question, namely that newly appointed senior or general managers should set clear boundaries and articulate their expectations to their staff regarding their philosophy and style:

I thought 'remember this' because this is the first time someone said to me 'I am your new boss, here is the box that I want you ...'. So for six months I wasn't going around saying shit, should I tell him or should I not tell him - where is the boundary?

The benefit of these boundaries was that they reduce insecurity in the minds, not just of the new manager but also in their team, which, in turn, creates the foundation for building relationships that empower the employees to share valuable knowledge required to make optimal decisions.

\section{Research question 4: What, if any, are the unique challenges of general manager transitions for general managers in South Africa?}

The majority of the interviewees felt that there were specific local issues. Only three of the interviewees could not identify any unique challenges for South African general managers. Instead, they discussed issues of a generic nature and considered these to be globally applicable. One participant commented that: '... every country has similar problems. It is actually frightening how synchronized the world is'.

Three themes specific to the South African environment were identified as: culture and diversity, Black Economic Empowerment and transformation.

South Africa has more diversity than most countries, and leaders who deal with diversity and diverse cultures experience challenges and opportunities since there is no standardised approach to managing diversity, as suggested by one of the respondents:

I have travelled the world and seen a lot of businesses - you follow a rule book. You know if you are faced with a particular situation you have a rule book generally to tell you what to do. And I think that is comforting for a lot of people, you know, people who are well qualified and even intelligent people, feel quite comfortable when someone has given them a rule book. In SA generally we don't work with rule books.

The local environment was also referred to by one of the interviewees as being less structured than some developed countries:

I think we do have unique transition challenges. I think if you take America, America is incredibly structured, even their management side is structured. You take Europe and again you go through the process before you get to management. In South Africa you are accelerating the environment. 
With reference to Black Economic Empowerment initiatives and so-called 'transformation', one interviewee expressed the opinion that:

I think that for me the major thing is in South Africa, if you want to be compliant your challenge is the cost of compliance has become very high because of the mobility of the black workers, of the skilled black work force.

The transformation agenda of South African businesses was also identified as a unique and ongoing challenge for general managers. The executives interviewed acknowledged that there is a need to address the historic imbalances and grow young black individuals into higher levels of the organisation: '... the problem that we would face now for instance, we still have an ongoing challenge around transformation'.

Some interviewees referred to racial issues. While such issues are not unique to South Africa, in their opinion they present specific challenges:

I think also it is probably quite difficult for white managers to sometimes manage, performance manage black staff, because there is always the fear of being called racist, and that whole race card thing and discrimination. So I think that is an added dynamic that you probably wouldn't have in other countries.

One participant referred to the need for targeted development but also commented that not enough is being done:

... that again is where mentorship becomes vitally important in organisations. It is not just, 'let's accelerate this mentorship', it's 'let's assign a dedicated strong leader' - and I am not saying a strong manager - a strong leader, to work with, particularly the accelerated management.

Another made the observation that: '... it is important to have our young black leaders and our young white leaders understanding that they lead everybody in these positions'.

The interviews suggested that South African leaders develop specific traits, which may be less evident in other environments, such as:

- Being resilient and able to adapt easily.

- Being more flexible.

- They tend to be younger leaders.

- They are able to manage diverse and dynamic cultures.

- They are good at managing conflict.

Interviewees remarked that these competencies are becoming more relevant internationally, particularly in dynamic markets. As a result, South African executives are likely to be sought after for global assignments.

\section{Discussion}

The results of this study confirmed the need to let go of certain behaviours but also emphasised the need to adapt particular competencies. From the interviews, four themes emerged as central to the successful transition to general management: letting go of control and maintaining ownership, personal characteristics and relationships, insecurities and courage in the face of loneliness.

The concept of letting go of power and control was a theme throughout the interviews. It was also highlighted as a contradiction: when managers are promoted to higher levels in an organisation, their level of power and authority increases, yet in order to be effective they needed to empower others, by letting go of power. This appears to align with the concept of the 'paradox of power' (Hill, 2006; De Klerk \& Stander, 2014). Many of the participants reported struggling to let go of control to truly empower others, and it was only after struggling through the process and gaining the relevant experience that they were able to develop this ability to let go. It seems that letting go of this power, control and responsibility is the only way to become effective. The results suggest that the leaders needed to learn how to 'lead through influencing' and not through power. What did become apparent was the difficulty experienced when having to do this under stressful conditions. Many reported that as soon as they faced stressful situations, they tended to fall back into their comfort zones and rely on doing functional and operational activities that they were familiar with and excelled at.

Letting go of control did not only relate to power and authority but also relate to key tasks and activities. The challenge described by the participants was trying to figure out what to let go of and delegate, and what to continue doing because it added value. This is not dissimilar to the 'continuity and discontinuity theory' perspective of De Meuse et al. (2011).

The importance of relationships was also emphasised in the interviews. Newly appointed general managers need to maintain and develop relationships across all levels. This finding supports another South African study conducted by Kanyangale and Pearse (2014), which identified the importance of mentors and colleagues for successful leadership development. Relationships need to extend to multiple levels, including not only vertical and horizontal relations but also external relations. Hill (2006) described this as a 'web of relations'. It is important to note that none of the themes that emerged can be viewed in isolation and are all linked. To relinquish power, it requires a level of trust, and to develop trust, one needs to build solid relations. These complex issues cannot be viewed as sequential and methodical in nature and require a high level of psychosocial skills. Letting go of power and control, the importance of relationships and building trust are components of 'emotional intelligence' referred to in the literature review. Successful leaders are self-aware, empathetic and possess social skills (Goleman, 1998). Building trust in a South African context takes particular skill and effort, given the country's history of conflict and division. Referring to Nelson Mandela's leadership style, Pietersen (2015) identified 'interpersonal leadership' - the capacity to understand others and bring out the best in them as one of Mandela's key attributes. 
The change in oneself and one's identity was a theme that emerged during the interviews. Some respondents reported feelings of insecurity, given that they were in unfamiliar territory. A strong theme that emerged was the need to adapt to the new environment: '... I think $99 \%$ of the time the guys that move into general management for the first time are completely overwhelmed ... you are treading water just faster and faster'. Despite the insecurities experienced by the participants, most of the interviewees displayed high levels of self-awareness. While they were questioning their own change in identity and who they were, they were aware of this self-reflection process. Participants also made mention of the fact that their mentors had played an important part in the process.

A key observation that emerged from the findings was the new level of responsibility that the general managers had to assume. They were now responsible for the 'whole', as opposed to only themselves as individuals: '... so having a heavy burden to bear does change how you look at things and does change you subtly'. Interviewees also referred to feelings of loneliness, and the courage required to handle it. Specific skills and behaviours which would be required by the aspiring general managers were the ability to communicate, build relationships and develop trust, let go and delegate, and have confidence in oneself.

The research probed the need to shift to strategic thinking and the challenges associated with adopting a different perspective (Boal, 2000; Kaplan \& Kaiser, 2003; Waldman \& Bowen, 2016; Watkins, 2012). It was important to understand to what extent the previous focus on highly operational, functional and tactical elements might impede the shift to strategic thinking (Casey \& Goldman, 2010).

The interviews revealed that there are differing views on what the shift to a strategic perspective entails, with no definitive conclusion. There was agreement that there must be an element of operational and tactical decision making to make strategic decisions. However, some interviewees felt that the senior manager's role was primarily executing on the strategy, whereas others reflected that they should be involved in strategy formulation and execution. The literature is unanimous about the fact that a shift is required. Watkins (2012) described it as the shift from 'tactician to strategist', whereas Kaplan and Kaiser (2003) referred to a need for a 'strategic leadership' approach at the general management level.

Interviewees all recognised the need to develop appropriate skills for the new role and the need to develop strategic perspectives. The areas of financial management skills and human capital management were considered to be the most important areas requiring development: '... the people challenge ... for me has been the biggest challenge because I struggle with that'. Burke (2006), De Meuse et al. (2011), Freedman (2005) and Ibarra et al. (2008) also referred to the need to develop the appropriate skills to facilitate the transition to general management. Interviewees reported that one of the biggest challenges in being able to adopt a strategic perspective was the ability to do so without having all the necessary information at their disposal. The most significant aspect was having to make decisions with incomplete information. The participants shared how they learned to gather information through ongoing learning, observation, informal channels and interactions. They emphasised the challenge of making decisions with less and less information. This is consistent with the literature, which suggests a process of having to know 'more and more about less and less' (Fauconnier, 2014).

The shift to a strategic perspective is one of the more significant distinctions between a manager and a leader (Goldman \& Casey, 2010). The manager may be extremely good at execution but may fail to make the shift to being able to adopt a strategic thinking perspective. Interviewees agreed that there is a need for development assistance to acquire the necessary skills and the ability to think strategically.

The framework proposed by Pietersen (2015) based on his analysis of Mandela's leadership style encapsulates key elements identified in the research: leaders need to master three domains - leadership of self, interpersonal leadership and strategic leadership.

The fourth research question dealt with the effectiveness of leadership development programmes. Writers such as Tucker (2013) and Prager (2016) have referred to a 'crisis of leadership' and questioned the effectiveness of management courses in dealing with this. The literature also provides contrasting views on the development of leaders and suggests that there is a need for further research in this area (Avolio, Walumbwa \& Weber, 2009; Burke, 2006; Day \& Harrison, 2007; Phillips, Ray \& Phillips, 2016).

It has been established that a manager needs to go through multiple change processes as part of the transition. However, the interviews confirmed that it is a deeply personal journey. It is not possible to rely solely on training programmes; a lot of what has to be learned can only come about through experience (Hall, 2008). Interviewees suggested that development programmes should focus on creating an awareness of what the manager will need to go through so that they are partially prepared and have some idea of what to expect. Ibarra et al. (2008) agreed that the focus of development must extend beyond training on skills and abilities, and must incorporate psychosocial aspects and processes. There was significant support from interviewees for the observation that personal and self-driven development initiatives are an essential aspect. This is consistent with the literature that also suggests the need for further research in respect of aligning personal development, leadership development and leadership effectiveness (Ibarra et al., 2008; Joiner \& Josephs, 2007; Khoreva \& Vaiman, 2015).

Building on the participant's feedback, a consolidated training process would include elements of formal training 
programmes, mentoring or coaching, practical skills development and informal aspects as illustrated in Figure 4.

The emphasis placed on coaching, mentoring and relationships in the interviews aligns with the notion of focusing on how leaders are taught, as opposed to what they are taught (Hackman \& Wageman, 2007).

Culture and diversity were highlighted by some as issues unique to South African managers who are transitioning to general management. Others argued that many countries also have challenges associated with culture and diversity. There was some support for the fact that the South African environment is more dynamic and less structured, thus enabling managers to use more initiative.

Nkomo and Kriek (2011) drew attention to the importance of 'change leadership' in the South African context and identified four themes that are also relevant to the findings in this study: embracing change, providing hope, connecting change to African values and culture, and championing diversity.

Black Economic Empowerment was also raised as a unique challenge for South African general managers. However, as noted above, it could also be argued that this is applicable to multiple levels of management transitions and not just the general manager level. The other aspect of Black Economic Empowerment impacting the transition is the challenge associated with having to deal with compliance issues. The manager may not have been prepared to deal with multiple compliancy issues; however, it could be claimed that this is part of the new responsibility that comes with the new role.
The concept of being responsible for a 'compliance' issue is not new, and it is only the individual compliancy issue itself, that may be unique.

The theme of transformation was related to issues of race and promotion, and how to deal with the challenges this exerts on issues such as performance management. However, once again, many managers around the globe who are transitioning to general management will face issues of dealing with different demographic factors. Perhaps, the only level of uniqueness is the extent to which these factors may differ from country to country.

\section{Limitations and recommendations}

A limitation of the research is the fact that 19 senior executives were interviewed for the study. Future research could broaden the scope to include more respondents. In addition, more general managers who had recently made the transition could be added to the sample.

The findings of the research demonstrate the challenges faced by managers making the transition to general management. They reinforce the findings of previous research (Ibarra et al., 2008; Sparrow \& Makram, 2015), which identifies this transition as one of the most difficult to make in a manager's career. South African organisations need to recognise the importance of facilitating this shift, and this study makes numerous practical suggestions as to the developmental programmes and processes, which can be implemented. Potential general managers also need to understand the challenges they will face and the steps they can take to succeed.

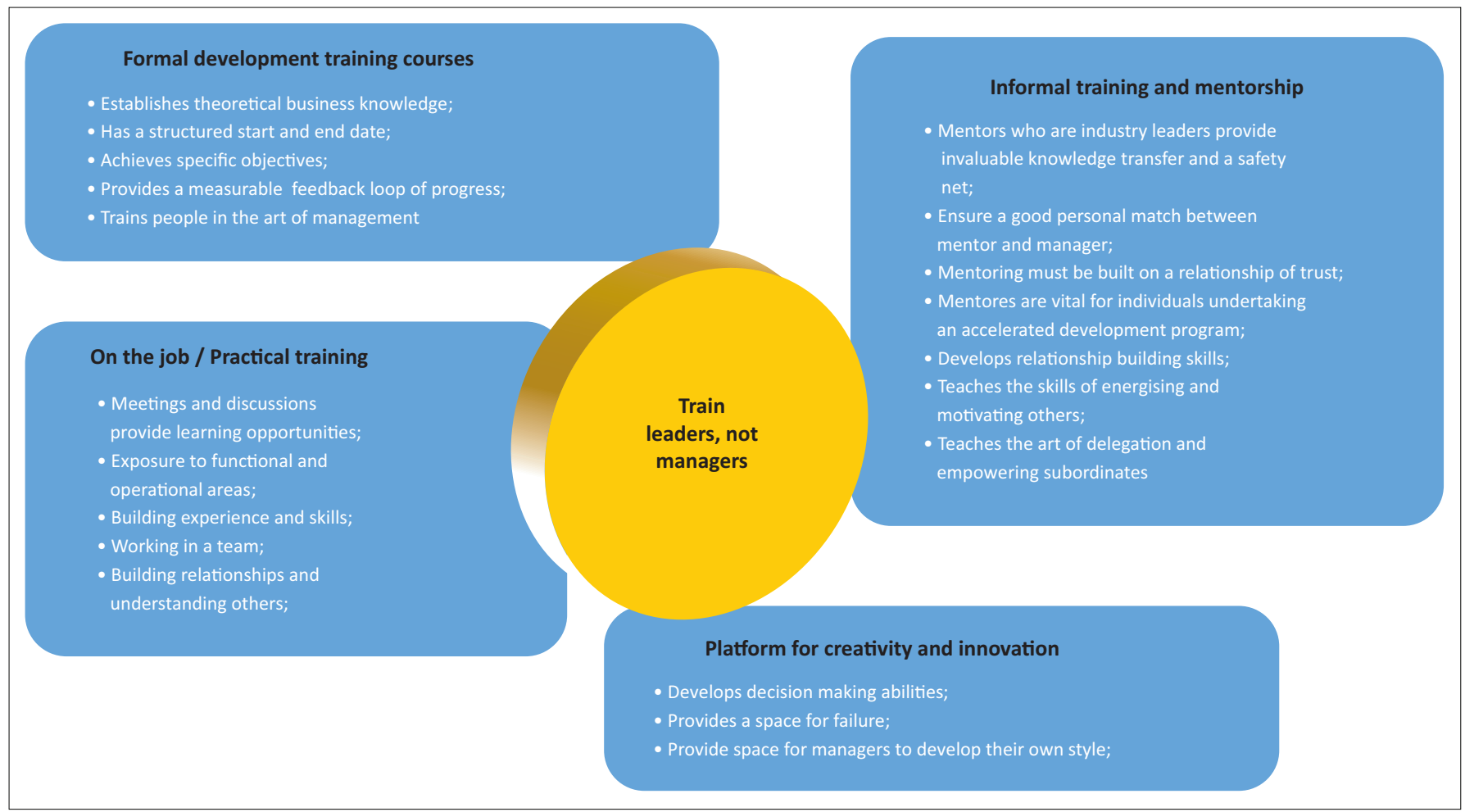

FIGURE 4: Consolidated leadership development. 


\section{Conclusion}

South African organisations face the challenge of developing employees at all levels if the country is to be globally competitive. There is a shortage of skilled workers, while supervisory and middle management levels are stretched and often lack the experience of their counterparts in developed economies. This study has focused on a critical level - general management - and the challenges of developing this leadership level within organisations. The South African context adds its own complexities, for example, the urgent need for transformation. A holistic approach is needed, which addresses elements ranging from education and mentoring, to providing appropriate work experience, to developing the skills, attitudes and personal characteristics to succeed as a general manager. Newly appointed general managers need to learn how to let go of control while maintaining ownership, build relationships and deal with the insecurities of making the transition. They also need to step up and make the shift from a tactical to strategic orientation and from management to leadership. They also need to realise that the decision to move from a functional role to the general management level should not be taken lightly. It is a fundamental shift requiring courage and a changed mind set. As general managers, they take on significant responsibility with many challenges but also with the opportunity to lead a part of the organisation and contribute to the growth of the economy.

\section{Acknowledgements Competing interests}

The authors declare that they have no financial or personal relationships that may have inappropriately influenced them in writing this article.

\section{Authors' contributions}

S.J.M. undertook the initial study as part of his MBA integrated research report at the Gordon Institute of Business Science, University of Pretoria. G.P. was the lead author who wrote up the study as an article for submission and who conducted the second review of the transcripts. K.H. was the supervisor of the MBA research project and contributed to the writing of the article.

\section{References}

Adl, R., Burnett, S., \& Dapra, R. (2013). Where have all the general managers gone? How high potentials can make the jump from functional, mid-level management faster. BTS. Retrieved June 26, 2016, from http://www.bts.com/docs/newsletter/ bts-insights-where-have-all-the-general-managers-gone.pdf?Sfvrsn=4

Avolio, B.J., Walumbwa, F.O., \& Weber, T.J. (2009). Leadership: Current theories, research, and future directions. Annual Review of Psychology, 60(1), 421-449. https://doi.org/10.1146/annurev.psych.60.110707.163621

Bandow, D., \& Self, T.B. (2016). Leadership at all levels: Developing managers to develop leaders. Journal of International Business Disciplines, 11(2), 60-74.

Bawany, S. (2016). NextGen leaders for a VUCA world. Leadership Excellence Essentials, 33(8), 43-44.

Berg, M.E., \& Karlsen, J.T. (2016). A study of coaching leadership style practice in projects. Management Research Review, 39(9), 1122-1142. https://doi. org/10.1108/mrr-07-2015-0157

Boal, K.B. (2000). Strategic leadership research: Moving on. Leadership Quarterly, 11(4), 515. https://doi.org/10.1016/S1048-9843(00)00057-6
Bonoma, T.V., \& Lawler, J.C. (1989). Chutes and ladders: Growing the general manager. Sloan Management Review, 30(3), 27-37.

Burke, R.J. (2006). Why leaders fail: Exploring the dark side. International Journal of Manpower, 27(1), 91-100. https://doi.org/10.1108/01437720610652862

Casey, A.J., \& Goldman, E.F. (2010). Enhancing the ability to think strategically: A learning model. Management Learning, 41(2), 167-185. https://doi.org/ $10.1177 / 1350507609355497$

Chiu, C.Y.C., Balkinud, P., \& Weinberg, F. (2016). When managers become leaders: The role of manager network centralities, social power, and followers' perceptions of leadership. Leadership Quarterly. https://doi.org/10.1016/j.leaqua.2016.05.004

Day, D.V., \& Harrison, M.M. (2007). A multilevel, identity-based approach to leadership development. Human Resource Management Review, 17(4), 360-373. https:// doi.org/10.1016/j.hrmr.2007.08.007

De Klerk, S., \& Stander, M.W. (2014). Leadership empowerment behaviour, work engagement and turnover intention: The role of psychological empowerment. Journal of Positive Management, 5(3), 28-45. https://doi.org/10.12775/jpm. 2014.018

De Meuse, K.P., Dai, G., \& Wu, J. (2011). Leadership skills across organizational levels: A closer examination. The Psychologist-Manager Journal, 14(2), 120-139. https:// doi.org/10.1080/10887156.2011.570143

De Vries, M.K., Sexton, J.C., \& Ellen, B.P, III. (2016). Destructive and transformationa leadership in Africa. INSEAD Working Papers Collection, no. 45, pp. 1-38 INSEAD, Fontainebleau, France.

Drotter, S. (2010). Leadership pipeline. Leadership Excellence, 27(8), 11-12.

Drotter, S., \& Charan, R. (2001). Building leaders at every level. Ivey Business Journal, 65(5), 21.

Fauconnier, C. (2014). The role of the general manager and the pitfalls of the transition. Johannesburg: Lecture-General Management Programme, Gordon Institute of Business Science.

Freedman, A.M. (1998). Pathways and crossroads to institutional leadership. Consulting Psychology Journal: Practice and Research, 50(3), 131-151. https:// doi.org/10.1037/1061-4087.50.3.131

Freedman, A.M. (2005). Swimming upstream: The challenge of managerial promotions. In R.B. Kaiser (Ed.), Filling the leadership pipeline (pp. 25-44). Greensboro, NC: Centre for Creative Leadership.

Freedman, A.M. (2011). Some implications of validation of the leadership pipeline concept: Guidelines for assisting managers-in-transition. The PsychologistManager Journal, 14(2), 140-159. https://doi.org/10.1080/10887156.2011. 570146

Goldman, E., Cahill, T., \& Filho, R.P. (2009). Experiences that develop the ability to think strategically. Journal of Healthcare Management, 54(2), 140-159.

Goldman, E., Wesner, M., \& Karnchanomai, O. (2013). Reciprocal peer coaching: A critical contributor to implementing individual leadership plans. Human Resource Development Quarterly, 24(1), 63-87. https://doi.org/10.1002/hrdq.21153

Goldman, E.F., \& Casey, A. (2010). Building a culture that encourages strategic thinking. Journal of Leadership \& Organizational Studies, 17(2), 119-128. https:// doi.org/10.1177/1548051810369677

Goldsmith, M., \& Reiter, M. (2007). What got you here won't get you there. New York: Hyperion.

Goleman, D. (1998). What makes a leader? Harvard Business Review, 76(6), 93-102.

Goleman, D., Boyatzis, R.E., \& McKee, A. (2013). Primal leadership: Unleashing the power of emotional intelligence. Boston, MA: Harvard Business Review Press.

Gosling, J., \& Mintzberg, H. (2003). The five minds of a manager. Harvard Business Review, 81(11), 54-63.

Hackman, J.R., \& Wageman, R. (2007). Asking the right questions about leadership. American Psychologist, 62(1), 43-47. https://doi.org/10.1037/0003-066X.62.1.43

Hall, G. (2008). Inside the theory of U. Reflections, 9(1), 41-46.

Hall, R.D., \& Rowland, C.A. (2016). Leadership development for managers in turbulent times. Journal of Management Development, 35(8), 942-955. https://doi.org/ 10.1108/JMD-09-2015-0121

Hellriegel, D., Jackson, S., \& Slocum, J. (2005). Management: A competency-based approach. (9th edn.). Mason, IA: South-Western.

Hill, L. (2003). Becoming a manager: How new managers master the challenges of leadership. (2nd edn.). Boston, MA: Harvard Business School Press.

Hill, L. (2006). Exercising Moral Courage: A Developmental Agenda. Chap. 12 in Moral Leadership: The Theory and Practice of Power, Judgment, and Policy, edited by Deborah L. Rhode, 267-290. San Francisco, CA: Jossey-Bass, 2006.

Hiller, N.J., DeChurch, L.A., Murase, T., \& Doty, D. (2011). Searching for outcomes of leadership: A 25-year review. Journal of Management, 37(4), 1137-1177. https:// doi.org/10.1177/0149206310393520

Ibarra, H., Snook, S., \& Ramo, L.G. (2008). Identity-based leader development. INSEAD Working Papers Collection, no. 32, pp. 1-36, INSEAD, Fontainebleau, France.

Joiner, W.B., \& Josephs, S.A. (2007). Leadership agility: Five levels of mastery for anticipating and initiating change. (1st edn.). San Francisco, CA: Jossey-Bass.

Kaiser, R.B. (2011). The leadership pipeline: Fad, fashion, or empirical fact? An introduction to the special issue. The Psychologist-Manager Journal, 14(2), 71-75. https://doi.org/10.1080/10887156.2011.570126

Kanyangale, M., \& Pearse, N. (2014). Developing leadership competencies: Insights from emergent junior talent-in-transitions in South Africa. International Journal of Organizational Leadership, 3, 56-79. 
Kaplan, R.E., \& Kaiser, R.B. (2003). Developing versatile leadership. MIT Sloan Management Review, 44(4), 19-26.

Kates, A., \& Downey, D. (2005). The challenges of general manager transitions. In R.B. Kaiser (Ed.), Filling the leadership pipeline (pp. 45-68). Greensboro, NC: Centre for Creative Leadership.

Keiser, K., Pich, M.T., \& Schecter, I.J. (2015). Becoming a top manager: Tools and lessons for transitioning into general management. San Francisco, CA: JosseyBass.

Kilner, A. (2015). Manager or specialist. Which role is most suitable for you? Holistic Marketing Management, 5(1), 6-10.

Khoreva, V., \& Vaiman, V. (2015). Intent vs. action: Talented employees and leadership development. Personnel Review, 44(2), 200-216. https://doi.org/10.1108/PR-102013-0191

Lazear, E.P. (2004). The Peter principle: A theory of decline. Journal of Political Economy, 112(1), S141-S163. https://doi.org/10.1086/379943

Lord, R.G., \& Hall, R.J. (2005). Identity, deep structure and the development of leadership skill. Leadership Quarterly, 16(4), 591-615. https://doi.org/10.1016/j leaqua.2005.06.003

Maroun, N. (2014). Role modeling key to valuable leadership. Retrieved January 18, 2015, from http://Irmg.co.za/news/entry/role-modeling-key-to-valuableleadership

McCall, M.W., Jr. (2004). Leadership development through experience. Academy of Management Executive, 18(3), 127-130. https://doi.org/10.5465/AME.2004. 14776183

Mintzberg, H. (1973). The nature of managerial work. New York: Harper \& Row.

Mumford, T.V., Campion, M.A., \& Morgeson, F.P. (2007). The leadership skills strataplex: Leadership skill requirements across organizational levels. Leadership Quarterly, 18(2), 154-166. https://doi.org/10.1016/j.leaqua.2007.01.005

Nicholson, H., \& Carroll, B. (2013). Identity undoing and power relations in leadership development. Human Relations, 66(9), 1225-1248. https://doi.org/10.1177/ 0018726712469548
Nkomo, S.M., \& Kriek, D. (2011). Leading organizational change in the 'new' South Africa. Journal of Occupational and Organizational Psychology, 84, 453-470. https://doi.org/10.1111/j.2044-8325.2011.02020.x

Pietersen, W. (2015). What Nelson Mandela taught the world about leadership. Leader to Leader, 76, 60-66. https://doi.org/10.1002/Itl.20180

Phillips, P., Ray, R., \& Phillips, J.J. (2016). How to capture the business value of leadership development. People \& Strategy, 39(2), 46-51.

Prager, H. (2016). How do we fix our leadership crisis? Talent Development, 70(3), 30-34.

Reimer, D., \& Meighan, S. (2017). Navigating the risks of leadership transitions. People and Strategy, $40(1), 40-45$.

Saunders, M., \& Lewis, P. (2012). Doing research in business and management. Edinburgh: Pearson.

Sokol, M. (2017). Leadership transitions: Common traps and timeless tactics. People and Strategy, 40(1), 14-17.

Sparrow, P.R. \& Makram, H. (2015). What is the value of talent management? Building value-driven processes within a talent management architecture. Human Resource Management Review, 25(3), 249-263. https://doi.org/10.1016/j.hrmr 2015.04.002

Tan, B. (2014). Successful leadership transition. Training \& Development (1839-8561) 41(2), 24-25.

Thomas, R.J. (2008). Crucibles of leadership development. MIT Sloan Management Review, 49(3), 15-18.

Tucker, E. (2013). What's behind the leadership shortage? Retrieved July 20, 2014, from http://www.hci.org/blog/whats-behind-leadership-shortage

Waldman, D.A., \& Bowen, D.E. (2016). Learning to be a paradox-savvy leader. Academy of Management Perspectives, 30(3), 316-327. https://doi.org/10.5465/amp. 2015.0070

Warner, M., \& Witzel, M. (1997). General management: Back to the future. Human Systems Management, 16(4), 263-276.

Watkins, M.D. (2012). How managers become leaders. Harvard Business Review, 90(6), 64-72. 